\title{
Therapeutic Effect of IL-4 Receptor-Targeting Pro-Apoptotic Peptide (API-ELP-KLAK) in Glioblastoma Tumor Model
}

\author{
Vijaya Sarangthem ${ }^{1,2, *}$ \\ Aena $\mathrm{Yi}^{\mathrm{l}}{ }^{*} *$ \\ Yunjae Kim ' \\ Alnawaz Rehemtulla ${ }^{3}$ \\ Byung-Heon Lee' \\ Young Hyun Jeon ${ }^{4}$ \\ Thoudam Debraj Singh ${ }^{5}$ \\ Rang-Woon Park (D) \\ 'Department of Biochemistry and Cell \\ Biology, School of Medicine, and Cell \& \\ Matrix Research Institute, Kyungpook \\ National University, Daegu, 4I944, \\ Republic of Korea; ${ }^{2}$ Department of \\ Pathology, All India Institute of Medical \\ Sciences (AlIMS), New Delhi, I I0029, \\ India; ${ }^{3}$ Department of Radiation \\ Oncology, University of Michigan, Ann \\ Arbor, MI, USA; ${ }^{4}$ Laboratory Animal \\ Center, Daegu-Gyeongbuk Medical \\ Innovation Foundation (DGMIF), Daegu, \\ Republic of Korea; ${ }^{5}$ Department of \\ Medical Oncology Laboratory, All India \\ Institute of Medical Sciences (AllMS), \\ New Delhi, I I0029, India \\ *These authors contributed equally to \\ this work
}

Correspondence: Rang-Woon Park Department of Biochemistry and Cell

Biology, School of Medicine, and Cell \&

Matrix Research Institute, Kyungpook

National University, Daegu, 41944,

Republic of Korea

Tel +82 534204822

Fax +8253422 I466

Email nwpark@knu.ac.kr

Thoudam Debraj Singh

Department of Medical Oncology

Laboratory, All India Institute of Medical

Sciences (AllMS), New Delhi, II 0029,

India

Email debraj.thoudam@gmail.com
Background: Thermal-responsive self-assembled elastin-like polypeptide (ELP)-based nanoparticles are an emerging platform for controlled delivery of therapeutic peptides, proteins and small molecular drugs. The antitumor effect of bioengineered chimeric polypeptide AP1-ELP-KLAK containing an interleukin-4 receptor (IL-4R) targeting peptide and pro-apoptotic peptide (KLAKLAK) was evaluated in glioblastoma (GBM) in vitro and in vivo.

Methods and Results: Herein, the therapeutic effect of AP1-ELP-KLAK was tested in advanced, and less curable glioblastoma cells with higher expression of IL-4R. Glioblastoma cell lines stably expressing different reporter systems i.e., caspase- 3 sensor (surrogate marker for cellular apoptosis) or effluc/enhanced firefly luciferase (cellular viability) were established to measure cell death non-invasively. Bioluminescence imaging (BLI) of D54/effluc and U97MG/effluc treated with AP1-ELP-KLAK exhibited higher cell death up to 2 3-fold than the control. Treatment with AP1-ELP-KLAK resulted in time-dependent increase of caspase-3 sensor BLI activity in D54/C cells and D54/C tumor-bearing mice. Intravenous injection of AP1-ELP-KLAK dramatically reduced tumor growth by inducing cellular apoptosis in D54/effluc tumor-bearing mice. Further, the immuno-histological examination of the excised tumor tissue confirmed the presence of apoptotic cells as well as caspase- 3 activation.

Conclusion: Collectively, AP1-ELP-KLAK effectively induced cellular apoptosis of glioblastoma cells and non-invasive imaging provides a window for real-time monitoring of antitumor effect with the provision of improving therapeutic efficacy in a glioblastoma mice model.

Keywords: tumor targeting, ELP, caspase-sensor, apoptosis, IL-4 receptor, glioblastoma

\section{Introduction}

Many drug delivery systems have improved clinical outcomes by regulating the pharmacological properties of anticancer drugs and transporting an effective optimum dose to the tumor, sparing normal tissue. ${ }^{1-3}$ Among the emerging class of drug carriers, ELP (elastin-like polypeptide) biopolymers serve as a novel vehicle for therapeutic drugs owing to their naturally derived sequence motifs or de novo engineered amino acid sequences generated through recombinant cloning methods. ${ }^{4}$ Since they are genetically engineered, the sequence and structure of these biopolymers can be precisely controlled at the genetic level. ${ }^{5}$ This allows fusion of other functional peptides or proteins domains along the coding sequence without 
affecting its structure and biological activities. ${ }^{6}$ Moreover, biocompatible, biodegradable and non-immunogenic properties make these biopolymers attractive alternatives to chemically synthesized polymers. ${ }^{7-10}$ ELPs can be tuned to assemble into nanoparticle-like structures at physiological temperature in aqueous solution while sustaining the bio-activity of fusion proteins. ${ }^{11-13}$ Many researchers have demonstrated that the fusion of cell-penetrating peptides or cancer-specific ligands to ELPs or diblock ELPs stimulates self-assembly into a spherical micelle-like structure and enhances cellular internalization, and extravasation at the tumor site. ${ }^{13-16}$ These stimuli-responsive nanoparticle ELPs were used to form ELP-drug conjugates with the aim to develop multifunctional nanomedicines for targeted cancer therapy. ${ }^{17,18}$

In an approach for the development of targeted drug carriers, overexpressed cell surface receptors or tumorassociated antigens have been tried to optimize cancer imaging and therapy. The robust expression of IL-4R on cancer cells, its implication on development of local metastasis and resistance to apoptosis was reported in several studies. ${ }^{19-21}$ The IL4-PE38KDEL cytotoxin is in clinical trials for various cancers such as metastatic breast cancer, kidney cancer, and non-small cell lung cancer. ${ }^{22}$ Previously, we discovered a IL-4R binding AP1 peptide by the phage display technique. ${ }^{23,24}$ Later, with the vision of inhibiting tumor growth using peptide drug delivery systems, an ELP-based multivalent targeting polymer (AP1-ELP) was successfully generated with tandem repeats of AP1 (IL-4R targeting peptide) incorporated along the ELP polymer backbone. ${ }^{25}$ Fusion of pro-apoptotic peptide (KLAKLAK) 2 referred to as KLAK into carboxy terminus of AP1-ELP led to the formation of micelles displaying a nanoparticle-like structure at physiological body temperature. Apart from providing a stable helical structure of KLAK peptide, the fusion AP1ELP-KLAK easily disrupt the cell membrane.

Motivated by this rationale, here, we evaluated the therapeutic effect of AP1-ELP-KLAK in glioblastoma cell lines in vitro and in vivo. The incidence of malignant gliomas is rising constantly and their prognosis is poor. Targeted therapy has been explored to treat glioblastoma tumors using cytotoxic drugs. Various human brain tumor cell lines have been known to express a high level of surface IL-4R. ${ }^{26,27}$ Earlier, we have reported the therapeutic effect of AP1-ELP-KLAK by measuring tumor size in MDA MB231 xenograft mice model and apoptosis mode of cell death by TUNEL assay of tumor tissue at the end of the therapy. ${ }^{28}$ Here, we used a non-invasive technique to monitor the apoptosis induced by AP1-ELP-KLAK in glioblastoma bearing animals using caspase-3 sensor. Previously, we have developed a highly sensitive caspase sensor, that can continuously measure cellular apoptosis non-invasively. ${ }^{29,30}$ During apoptosis, active caspase-3 cleaves the reporter at a DEVD sequence (Asp-Glu-ValAsp), leading to high-affinity association of NLuc and CLuc fragments, giving a strong luciferase activity. Unlike the traditional way of measuring apoptosis, the caspase-3 sensor system gives a sensitive and quantitative approach for evaluating apoptosis in a non-invasive manner. Thus, in this study, we tried monitoring AP1-ELPKLAK induced apoptosis in stably caspase-3 sensor expressing glioma cells in vitro and in vivo (Figure 1). Real time monitoring of bioluminescence imaging (BLI) from the caspase-3 sensor activity corresponds to apoptosis occurring in the tumor. For overall therapy studies, mice xenograft bearing glioma cells with stable expression of enhanced firefly luciferase (effluc) were used and BLI activity was obtained from tumor that corresponds to tumor growth.

\section{Materials and Methods}

\section{Reagents}

D-Luciferin was purchased from Perkin Elmer, glosensor (Promega), Z-VAD (Tocris Bioscience), all the other chemicals and reagents required for cell culture including antibiotics, fetal bovine serum (FBS), media were obtained from Invitrogen. Annexin V-PI apoptosis detection kit (BD Biosciences), APC anti-human CD124 (IL-4R $\alpha$ ) and IgG isotype antibody were procured from Biolegend.

\section{Cell Culture}

Two different human glioblastoma cell lines D54 and U87MG from ATCC were grown in RPMI-1640 medium with $10 \% \mathrm{FBS}, 100 \mathrm{U} \mathrm{mL}^{-1}$ of penicillin/streptomycin and GlutaMAX at $37^{\circ} \mathrm{C}$ in a humidified atmosphere containing $5 \% \mathrm{CO}_{2}$.

\section{IL-4R Expression Analysis}

The expression of IL-4R in D54, U87MG was measured by flow cytometry after incubating $\left(1 \times 10^{6}\right)$ cells with APC anti-human CD124 (IL-4R $\alpha$ ) and IgG isotype antibodies for $1 \mathrm{~h}$ at $4^{\circ} \mathrm{C}$. After thorough washing of the cells, a minimum of 20,000 events were recorded and the percentage of IL-4R expression in the glioma cells was obtained by comparing with isotype. 


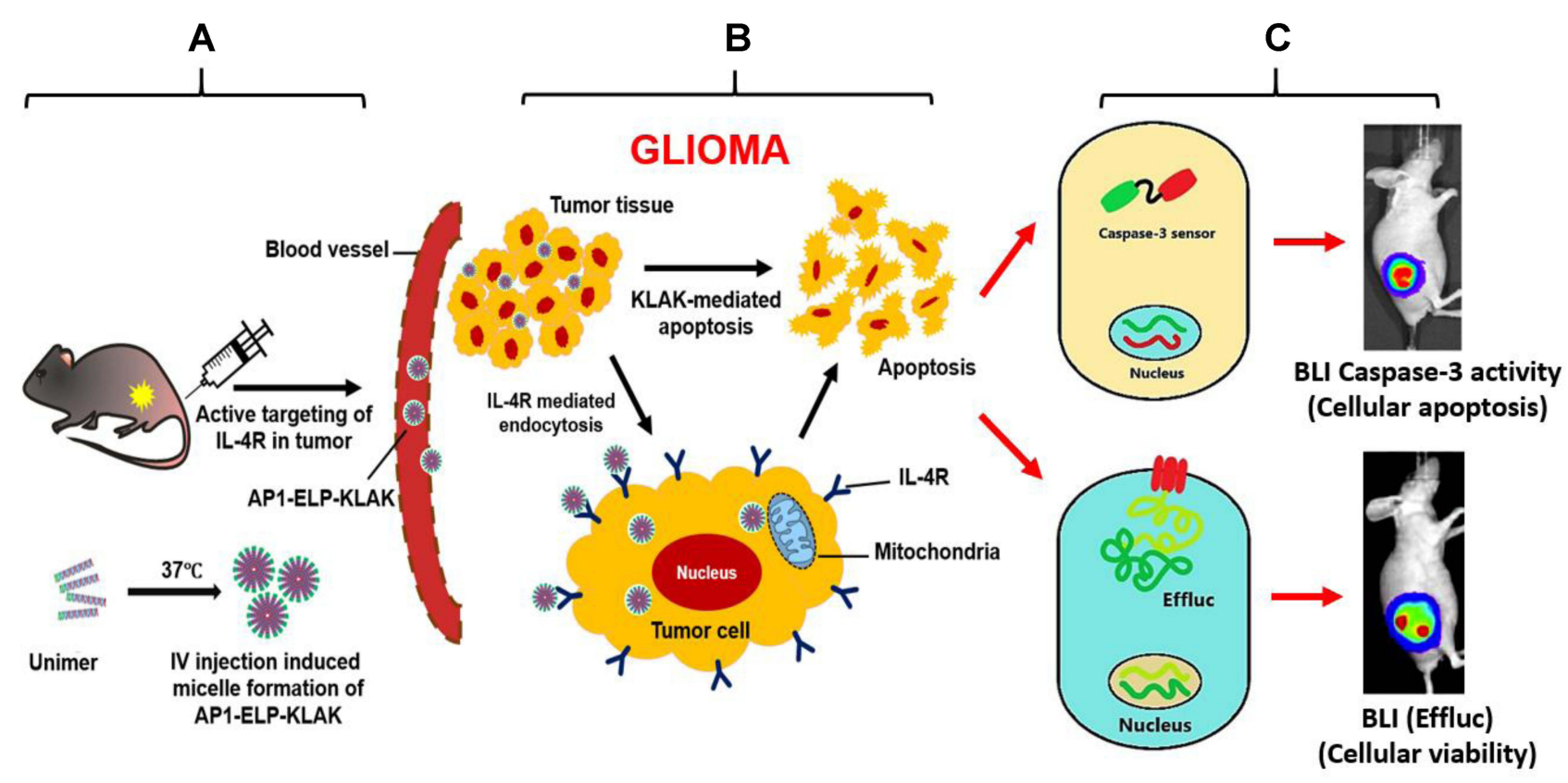

Figure I Schematic diagram for non-invasive imaging of API-ELP-KLAK induced apoptosis in glioblastoma mouse model. (A) Systemic administration of API-ELP-KLAK in glioblastoma bearing mice. (B) Uptake of API-ELP-KLAK by glioma via IL-4R receptor mediated endocytosis and EPR effect, causing massive apoptosis of tumor tissue. (C) Real-time monitoring of apoptosis by caspase-3 sensor and cellular viability by effluc reporter system stably expressed in glioblastoma cells.

\section{Establishment of Glioma Stable Cell Lines}

For real time monitoring of cell viability, D54 and U87MG were transduced with retrovirus expressing effluc (Enhanced firefly luciferase) ${ }^{31}$ and sorted using a flow cytometer. The stable glioma cells expressing effluc were referred to as D54/effluc or U87MG/effluc cells. To monitor apoptosis in real-time, a D54 expressing caspase- 3 sensor stable cells line was used that had been established in our previous studies. ${ }^{32,33}$ Briefly, D54 cells were transfected with the caspase-3 sensor construct using Fugene 6 (Roche), and subjected to known concentration of G418 for stable clone selection. The stable D54 cells expressing the caspase-3 sensor were referred to as D54/C cells.

\section{Synthesis and Protein Purification of KLAK Containing ELP Polypeptides}

Proteins were expressed and purified as done previously. ${ }^{25}$ Briefly, the transformation of pET $25 b+$ vector with ELPKLAK and AP1-ELP-KLAK genes was done using BL21 competent E. coli cells. Transformed E. coli cells were inoculated in $10 \mathrm{~mL}$ starter culture of Circle grow media (MP Biomedicals) supplemented with $100 \mu \mathrm{g} \mathrm{mL} \mathrm{m}^{-1}$ of ampicillin and grown overnight in a shaking incubator. Next day, the starter cultures were added to $800 \mathrm{~mL}$ of Circle grow media and kept in a shaker incubator until the optical density reached around $0.8-1$. Then, the protein synthesis was initiated by adding $1 \mathrm{mM}$ IPTG for 4 h. Harvested cells were suspended in $10 \mathrm{~mL}$ of phosphatebuffered saline (PBS). The inverse transition cycling (ITC) method was adopted to purify the ELP protein. ${ }^{34,35}$ A minimum of three rounds of ITC were performed to get pure protein, followed by SDS-PAGE and copper chloride staining to confirm the molecular weight.

ELP proteins were filtered using a $0.2 \mu \mathrm{M}$ Whatman syringe filter and the concentration was measured by Cary UV-visible spectrophotometer. The accurate molecular weight of these polypeptides was determined using MALDI-TOF/TOF MS. For further validation of nanoparticles size, polypeptides were suspended in $0.9 \%$ saline (sodium chloride, $\mathrm{NaCl}$ ), incubated at $37^{\circ} \mathrm{C}$ for $10 \mathrm{~min}$ and cryo-TEM images was taken using FEI Tecnai transmission electron microscope. The turbidity profiles and particle sizes was determined using Cary UV-visible spectrophotometer and dynamic light scattering (DLS), respectively. All the protocols of purification and characterization were replicated from our previous work. $^{25,28}$

\section{In vitro Bioluminescence Imaging (BLI)}

For luciferase assay, $1 \times 10^{4}$ of D54/effluc or U87MG/effluc cells/well were seeded in 96-well black plates with clear 
bottoms. Next day, $3 \mu \mathrm{L}$ D-luciferin $(30 \mathrm{mg} / \mathrm{mL})$ was added in each well and followed by BLI measurement using IVIS Lumina III (PerkinElmer).

\section{In vitro Caspase 3 Activation (BLI)}

D54/C cells $\left(1 \times 10^{4} /\right.$ well $)$ was seeded in clear-bottomed 96-well black plates. After 24 hours, different concentrations of ELP-KLAK and AP1-ELP-KLAK were treated and were switch to $\mathrm{CO}_{2}$-independent culture medium supplemented with $1 \%$ Glosensor and 10\% FBS. The caspase3 sensor BLI activity was measured at different time interval using IVIS Lumina III. In order to inhibit caspase activation, the ELP-KLAK and AP1-ELP-KLAK treated cells were then treated with $20 \mathrm{mM} \mathrm{Z-VAD} \mathrm{(pan-caspase}$ inhibitor), for an additional 1 hour and the BLI activity was obtained accordingly.

\section{In vivo Caspase 3 Sensor Activity and Therapy Studies}

D54/C cells $\left(5 \times 10^{6}\right)$ were subcutaneously implanted into the right hind flanks of BALB/c nude mice (Japan SLC Inc., Shizuoka, Japan). After 14 days, all 3 groups $(\mathrm{n}=10)$, a control group (ELP treatment) and 2 therapy groups (ELP-KLAK and AP1-ELP-KLAK treatment) were given IV injection of respective proteins $(150 \mathrm{mg}$ $\mathrm{kg}^{-1}$ ) for 3 days. BLI from caspase-3 activation was obtained using an IVIS Lumina III immediately before injection at day 0 , day 3 and day 5. For BLI, each mouse received a single dose of substrate (d-luciferin $3 \mathrm{mg} / \mathrm{mouse}$ ) (Figure S5). Mice were anesthetized and serial images were acquired for $20-30 \mathrm{~min}$ and the peak luminescence values were obtained from region of interest (ROI). For ex vivo analysis of apoptosis in D54/C tumors, excised tumor tissue was fixed with $4 \%$ paraformaldehyde and rapidly frozen. Tumor sections $(5 \mu \mathrm{m}$ thick) were stained with anti-cleaved caspase-3 antibody (Cell Signaling; 1:100), followed by Alexa 564-labeled secondary antibody (1:200), DAPI for nuclear staining and the images were captured using a confocal microscope.

For in vivo therapy studies, D54/effluc cells were implanted in BALB/c nude mice, and after 2 weeks, mice were divided into four groups, 2 control groups: PBS and ELP only and 2 therapy groups: ELP-KLAK and AP1-ELP-KLAK respectively ( $\mathrm{n}=10$ per group). Mice were given a single dose IV injection daily with the respective proteins $\left(150 \mathrm{mg} \mathrm{kg}^{-1}\right)$ or PBS for 8 days
(Figure S6). Before and during therapy, BLI was acquired to monitor cellular viability for therapeutic response at the indicated times. ROI were drawn in tumor region of each mouse, and the peak luminescence values were calculated. Simultaneously, body weight and tumor volume (formula: Volume in $\mathrm{mm}^{3}=$ (width ${ }^{2} \times$ length) $/ 2$, were also recorded every alternate day. Post therapy, mice were sacrificed, the excised tumor volumes were recorded and analyzed. All in vivo studies were strictly conducted as per recommendations of the National Institutes of Health (NIH). All the animal experiments were conducted with prior approval from the Animal ethics committee of Kyungpook National University (Permit Number: KNU 2015-0043).

\section{Statistical Analysis}

Statistical significance was performed by Student's $t$-test, One way or two-way ANOVA for comparison of two or multiple groups. ${ }^{* * *} \mathrm{P}<0.001,{ }^{*} * \mathrm{P}<0.01$, and $* \mathrm{P}<0.05$ were considered.

\section{Results}

\section{Protein Expression and Biophysical Characterization}

The ELP-KLAK and AP1-ELP-KLAK was successfully bio-engineered by recursive directional ligation (RDL) method. ${ }^{25}$ The plasmids harboring the genes of respective polypeptides were further transformed with competent BL21 E. coli for protein expression. The polypeptides were purified via inverse thermal cycling (ITC) and the apparent molecular weight and purity was confirmed by SDS-PAGE (Figure 2). A single band corresponding to respective polypeptides was detected on the gel with minimal contamination after 3 rounds of ITC. The accurate molecular weight of ELP-KLAK $(35,474.8 \mathrm{Da})$ and AP1-ELP-KLAK $(43,619.8$ Da) was validated using MALDI-TOF/TOF MS before other studies (Table 1). The self-assembly of the polypeptides into nanoparticles at physiological temperature was confirmed using cryoTEM after incubation at $37^{\circ} \mathrm{C}$, similar to our previous work. $^{28}$

\section{Analysis of IL-4R Expression and Cellular Interaction of API-ELP-KLAK}

The expression level of IL-4R checked using flow cytometry showed up to $36 \pm 4 \%$ in U87MG cells, and 
A

$\sim M M$

[(VPGVG) $\left.{ }_{14}\right]_{6}-(\text { KLAKLAK })_{2}$

ELP-KLAK
Self-assembled at $37^{\circ} \mathrm{C}$
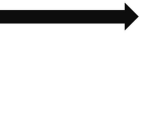

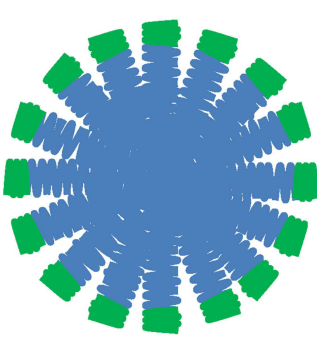

Cryo TEM

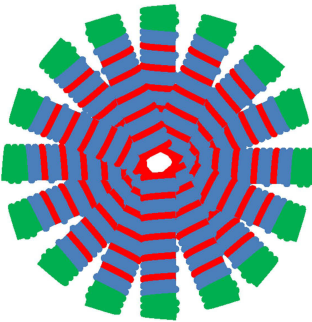

Self-assembled nanoparticle
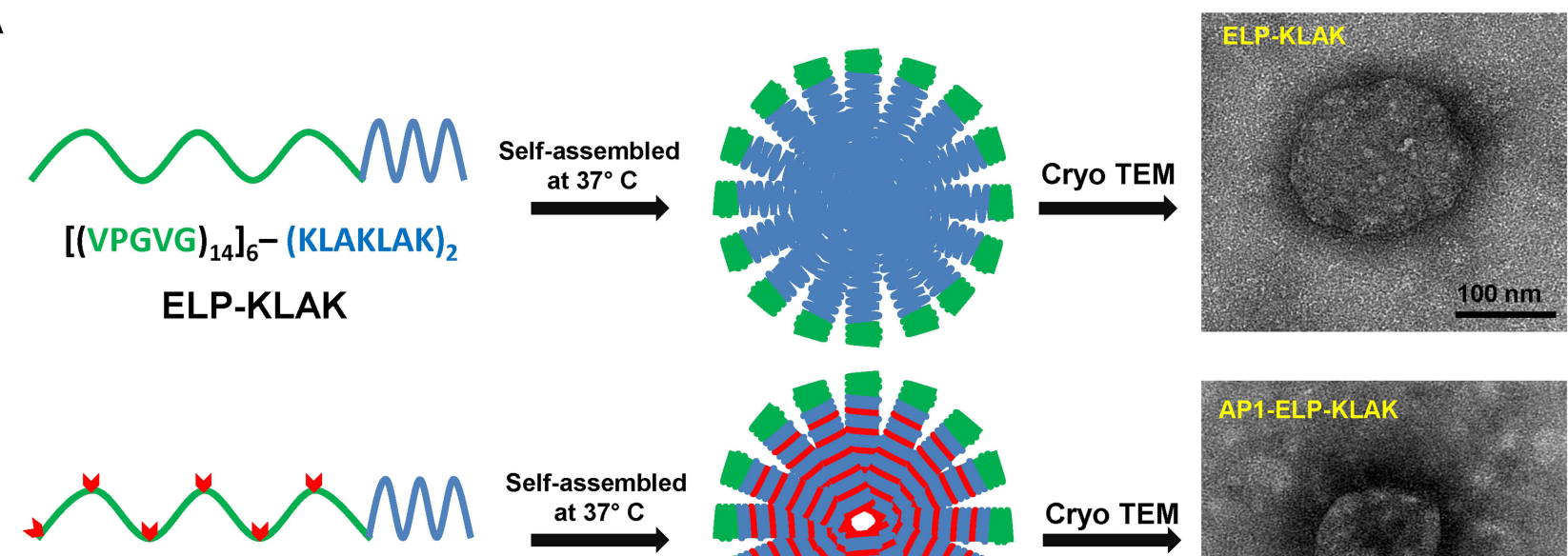

[RKRLDRN - (VPGVG) $\left.{ }_{12}\right]_{6}-($ KLAKLAK) 2 AP1-ELP-KLAK

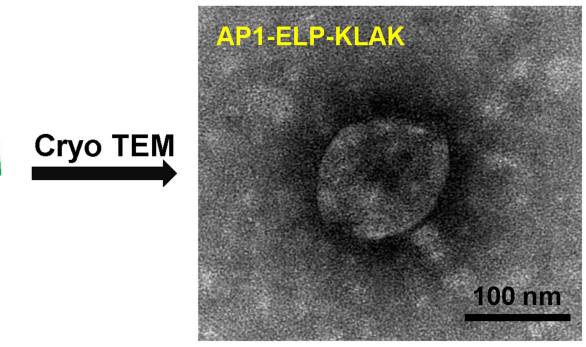

B

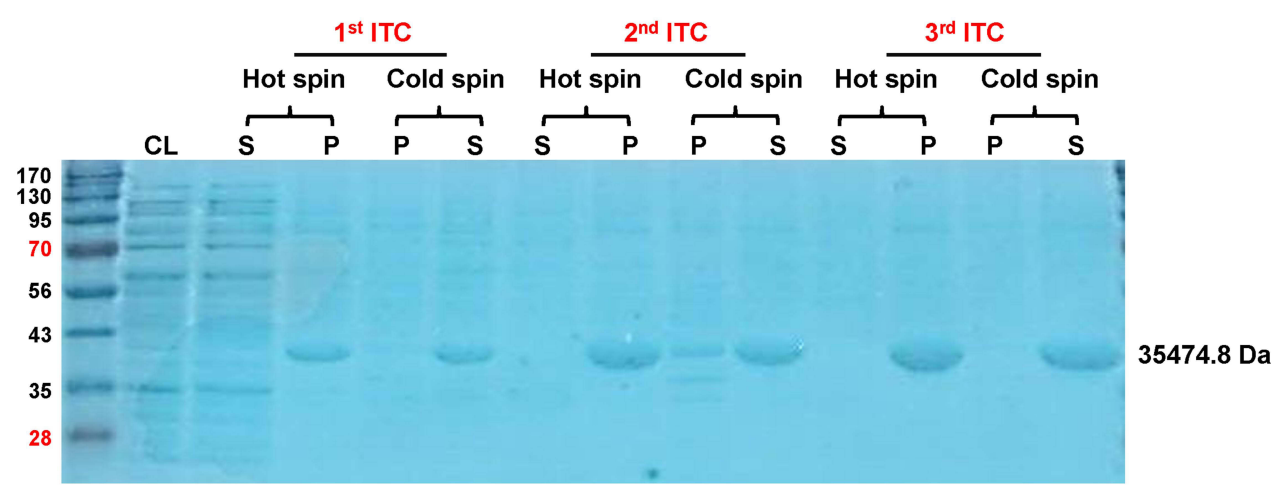

C

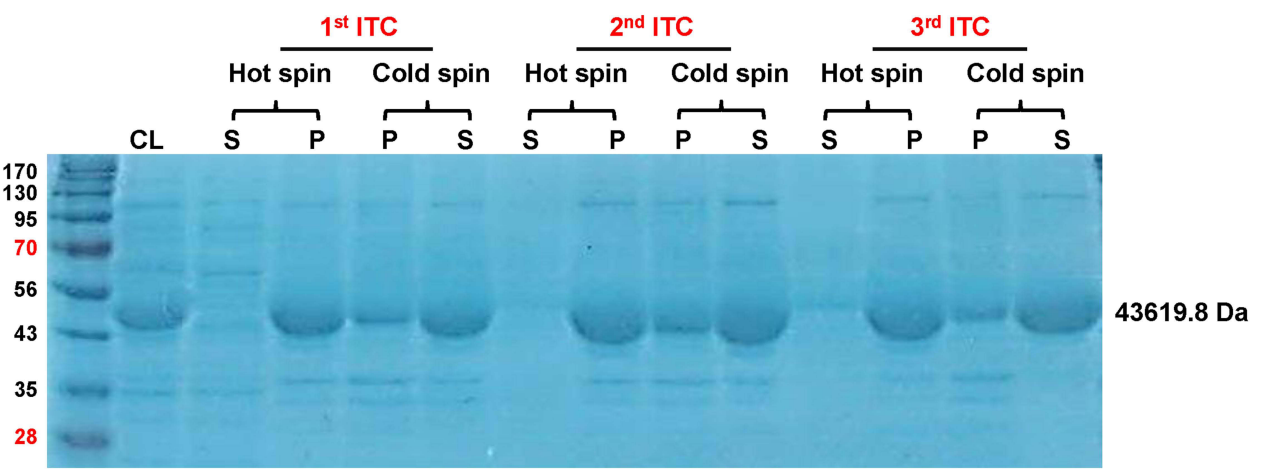

Figure 2 Characterization of ELP-KLAK and API-ELP-KLAK. (A) The structure of ELP-KLAK and API-ELP-KLAK along with coding sequence of the polypeptides. Both the polypeptides underwent phase transition and retained as nanoparticle-like structures at $37^{\circ} \mathrm{C}$. Cryo-TEM of self-assembled ELP-KLAK and API-ELP-KLAK. Scale bar, I00 nm. (B) ELP-KLAK and (C) API-ELP-KLAK, SDS-PAGE (10\%) of polypeptides purified using ITC. After 3rd ITC single band for each polypeptide were observed indicating high level of purity. Molecular weight (in KDa) of the polypeptides were indicated on the right.

Abbreviations: $\mathrm{CL}$, total cell lysate; S, supernatant; P, pellet; ITC, inverse temperature cycling.

relatively higher up to $50 \pm 5.5 \%$ in D54 cells (Figure 3A and B). After the confirmation of IL-4R expression, the ability of self-assembly by KLAK-containing polypeptides to recognize and selectively bind to IL-4R receptors was assessed on glioblastoma cell lines. Confocal microscopy results showed a relatively stronger binding of AP1-ELPKLAK on IL-4R-overexpressing D54 (Figure S1) and 
Table I Physical Characteristics of ELP-KLAK and API-ELP-KLAK

\begin{tabular}{|l|l|l|l|}
\hline Protein & $\begin{array}{l}\text { Molecular } \\
\text { Weight (Da) }\end{array}$ & $\begin{array}{l}\text { Critical Micelle } \\
\text { Temperature }\left({ }^{\circ} \mathbf{C}\right)\end{array}$ & Size (nm) \\
\hline $\begin{array}{l}\text { ELP-KLAK } \\
\text { API-ELP- }\end{array}$ & $35,474.8$ & $34-45^{\circ} \mathrm{C}$ & $180 \sim 210 \mathrm{~nm}$ \\
KLAK & & $34-42^{\circ} \mathrm{C}$ & $110 \sim 130 \mathrm{~nm}$ \\
\hline
\end{tabular}

U87MG (Figure S2) cells at $4^{\circ} \mathrm{C}$. However, D54 and U87MG cells internalized AP1-ELP-KLAK at $37^{\circ} \mathrm{C}$, while no internalization of ELP-KLAK was observed in U87MG and D54 cells (Figure 3C and D) respectively. Thus, the presence of AP1 ligand allowed the multivalent interaction of AP1-ELP-KLAK with cell surface receptors followed by IL-4R mediated endocytosis in glioblastoma cells.

\section{Cell Viability Assay}

After validation of cellular association by AP1-ELPKLAK, we next determined their ability to deliver KLAK peptide intracellularly by assessing the level of cytotoxicity in vitro. Before performing the cytotoxic experiments, we confirmed the stable expression of enhanced firefly luciferase (effluc) reporter gene in U87MG/effluc and D54/effluc cells by luciferase assay in 96-well black plates. Luciferase activity was found to increase in a cell-dependent manner in both U87MG/effluc and D54/effluc cells, respectively (Figure S3). Cell proliferation assays of the stable D54/effluc and U87MG/effluc cells and respective parental D54 and U87MG cells were performed using CCK-kit after seeding equal numbers of cells in 96well plates. We confirmed that the stable expression of effluc genes does not alter their proliferation rate as both the parental and stable gliomas cells showed similar proliferation rates at $24 \mathrm{~h}$ and $48 \mathrm{~h}$ (Figure S4). The cytotoxic effect was checked after 24 $\mathrm{h}$ treatment of different concentrations of KLAK polypeptides in U87MG/effluc and D54/effluc cells. The control polypeptides AP1-ELP and ELP-KLAK did not cause any significant cytotoxic effect even at higher concentrations, whereas AP1-ELP-KLAK caused cell death in a dose-dependent manner in U87MG/effluc (Figure 4A and B) and D54/effluc cells (Figure $4 \mathrm{C}$ and $\mathrm{D}$ ). At the highest concentration 10 $\mu \mathrm{M}$, AP1-ELP-KLAK caused almost $\sim 3$ fold higher cell death than ELP-KLAK in D54/effluc and in U87MG/effluc cells, it showed $\sim 2$-fold higher antiproliferative activity. These results further confirmed that the cytotoxic activity of these polypeptides mainly depends on IL-4R expression and its interaction with AP1-ELP-KLAK.

\section{Real Time Monitoring of Caspase-3} Dependent Apoptosis in vitro

For the real time monitoring of apoptosis in vitro, D54 cells stably expressing caspase-3 sensor (D54/C) cells were treated with KLAK polypeptides. As depicted in Figure 4A and B, treatment of AP1-ELP-KLAK significantly increased BLI activity in a time- and dosedependent manner, but treatment of ELP-KLAK did not result in any significant increase. The BLI activity peaked at 6 hin all concentrations of AP1-ELP-KLAK. Caspase-3 sensor BLI activity were $\sim 5$ and $\sim 6$-fold higher than the PBS treated cells at $6 \mathrm{~h}$, respectively in 2.5 and $5 \mu \mathrm{M}$ of AP1-ELP-KLAK treated cells (Figure 5A and B).

We further confirmed the selectivity of the caspase- 3 sensor in $\mathrm{D} 54 / \mathrm{C}$ cells by treating Z-VAD, a well-known caspase inhibitor along with AP1-ELP-KLAK. The increase in the BLI activity after treatment of AP1ELP-KLAK was completely inhibited after coincubation of $20 \mu \mathrm{M}$ of Z-VAD and AP1-ELP-KLAK (Figure $5 \mathrm{~A}$ and $\mathrm{B}$ ). The rapid and early increase in BLI (caspase-3 activity) upon AP1-ELP-KLAK treatment and returning to basal level on addition of Z-VAD confirmed the selectivity and sensitivity of the caspase-3 reporter.

\section{Apoptosis Assay Using Annexin V/PI}

To validate the apoptosis induction in IL-4R expressing glioma cells, Annexin V staining was adopted, which is a gold standard for apoptosis measurement. To determine the rate of apoptosis induced after AP1-ELPKLAK treatment, U87MG and D54 cells were stained with Annexin V. We observed a concentrationdependent increase of Annexin V-positive cells in both AP1-ELP-KLAK treated cell lines. At $20 \mu \mathrm{M}$ of AP1- ELP-KLAK, $75 \pm 5.5 \%$ of D54 cells undergo apoptosis but not in ELP-KLAK treated cells (Figure 6C and D). Likewise, AP1-ELP-KLAK caused $62 \pm 5.5 \%$ apoptosis in U87MG cells (Figure 6A and $\mathrm{B})$, confirming the percentage of apoptosis depends on 
A

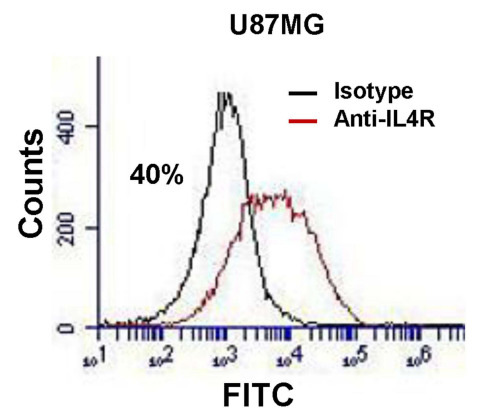

C

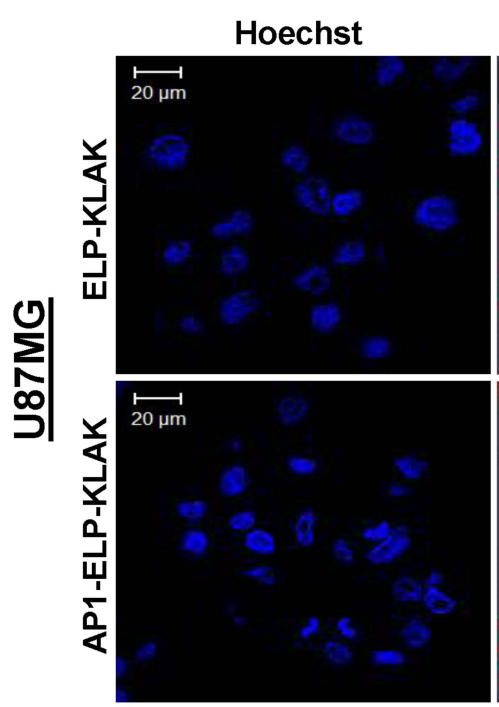

D

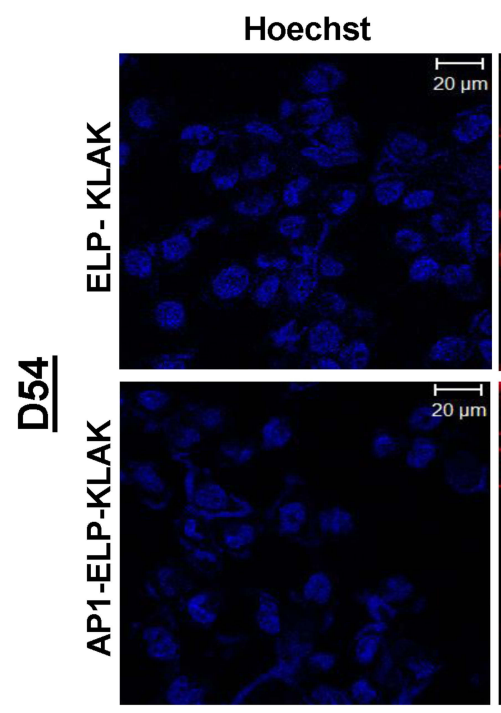

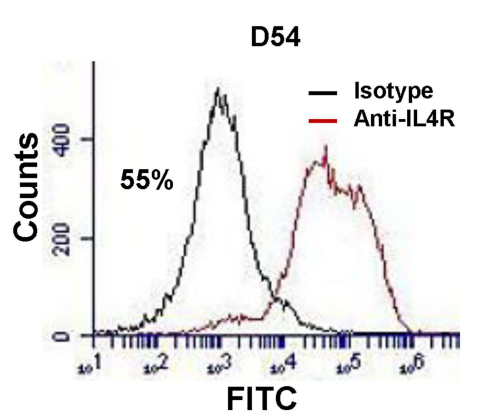

B

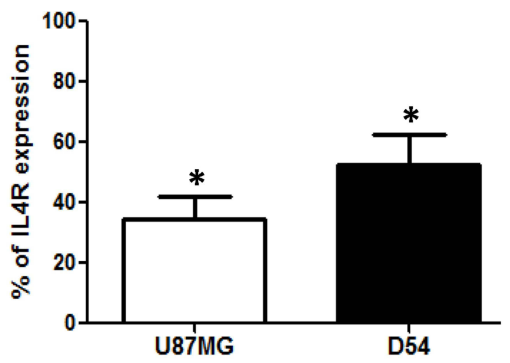

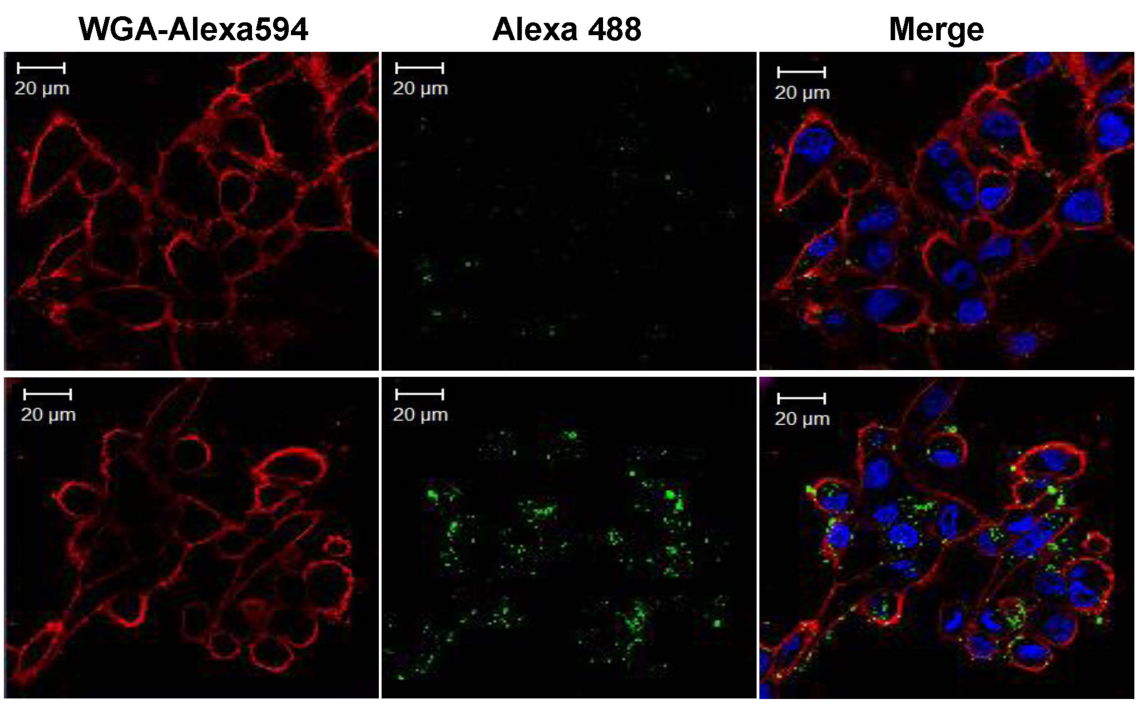

Figure 3 Assessment of IL-4R expression and cellular uptake assay. (A) Representative histogram of IL-4R expression analyzed through flow cytometry after staining with anti-IL-4R $\alpha$ antibody. (B) Percentage of IL-4R expression in different cancer cells was analyzed by comparison with respective lgG isotype control $(n=3)$. *P<0.05, (Student's $t$-test). Cellular uptake and internalization of fluorescently labeled polypeptides by (C) U87MG and (D) D54 at $37^{\circ} \mathrm{C}$. Cell membrane stained with WGA Alexa 594 and nuclei stained with Hoechst. Scale bar, $20 \mu \mathrm{m}$.

IL-4R over-expressing in glioma cells. The rate of apoptosis in D54 cells after AP1-ELP-KLAK treatment is consistent with BLI activity of caspase-3 sensor of
D54/C (Figure 5). Thus, AP1 peptides along the ELP polymers enhanced apoptosis of cancer cells by active targeting of IL-4R. 
A

U87MG/effluc

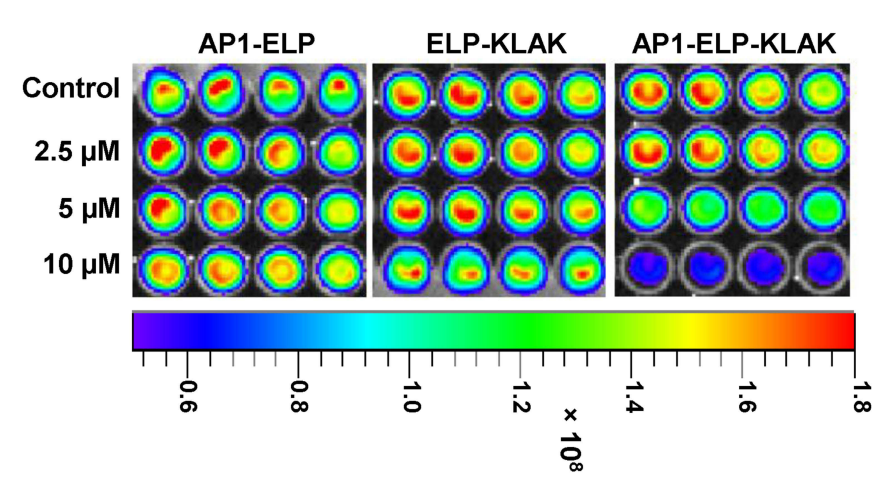

C

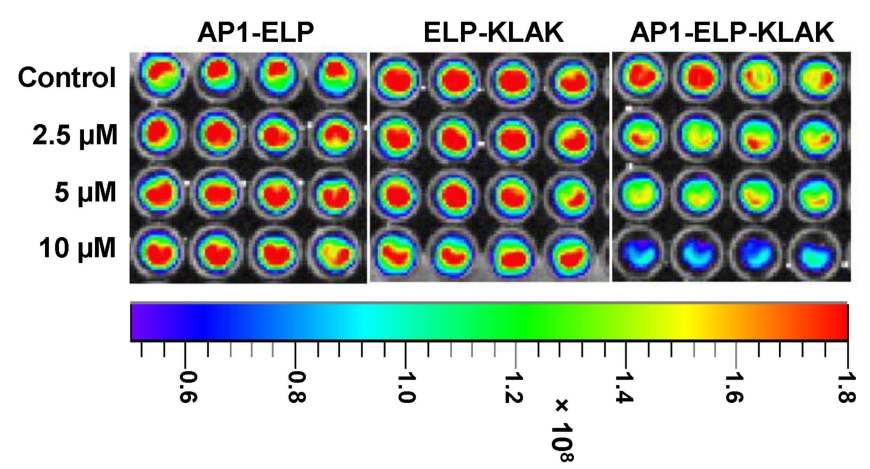

B

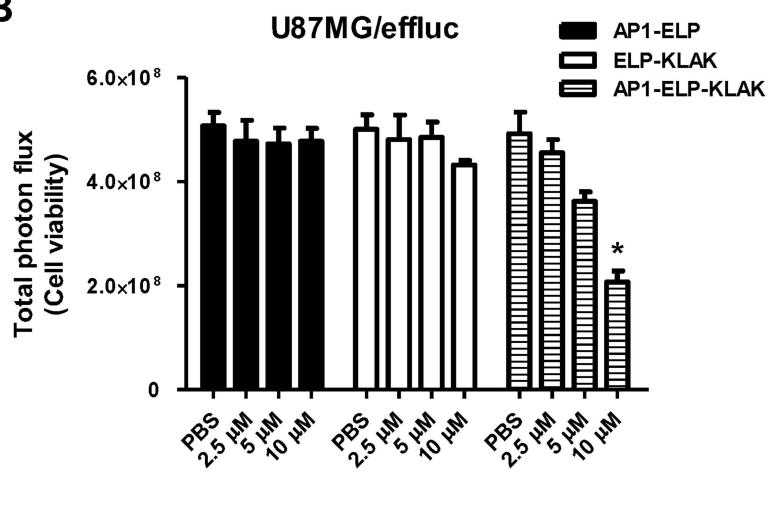

Figure 4 API-ELP-KLAK induced cytotoxicity in glioblastoma cells. (A and C) Luciferase activity of U87MG/effluc cells and (B and D) D54/effluc cells were determined after adding $3 \mu \mathrm{L}$ D-luciferin $\left(30 \mathrm{mg} \mathrm{mL}^{-1}\right)$ in each well, and then the bioluminescence signals were measured using an IVIS Lumina III in vivo imaging system. Data are represented as mean \pm s.d. $(n=5)$. ${ }^{*} P<0.05$ (one-way ANOVA).

\section{Non-Invasive Imaging of Caspase-3 Activity in D54/C Cells in vivo}

Herein, we measured the apoptosis in a non-invasive manner using a stably expressing caspase-3 sensor D54/C cells in vivo. After daily treatment of respective KLAK polypeptides $\left(150 \mathrm{mg} \mathrm{kg}^{-1}\right)$ for 3 days in D54/C tumor-bearing mice, BLI was acquired to monitor caspase- 3 activation at different time points (Figure S5). BLI of caspase-3 sensor was performed immediately before injection at day 0 , day 3 and day 5 after administration of ELP-KLAK and AP1-ELPKLAK. We observed a significant increase of BLI activity of caspase-3 sensor in AP1-ELP-KLAK treated group with peak at day 5, whereas no such increase of caspase-3 BLI activity were seen in control and ELP-KLAK treated groups at day 3 and day 5 respectively (Figure 7A and B). Additionally, ex vivo immuno-histochemical staining of D54/C tumors with anti-cleaved caspase-3 antibody further confirmed massive apoptosis only in AP1-ELP-KLAK treated tumor with more cleaved caspase- 3 positive cells than the control ELP and ELP-KLAK treated tumors at day 5 (Figure 7C).

\section{Anti-Tumor Effect of API-ELP-KLAK in vivo}

According to the BLI of caspase-3 sensor obtained (Figure 7), the apoptosis was shown to be maximum at day 5 after 3 days of daily treatment of AP1-ELPKLAK. Next, for the better therapeutic efficacy, D54/ effluc tumor-bearing mice were given a single dose of $150 \mathrm{mg} \mathrm{kg}^{-1}$ of polypeptides daily for 8 days via intravenous (IV) injection (Figure S6). A significant reduction of BLI of effluc (surrogate marker for cell proliferation) was obtained in AP1-ELP-KLAK treated mice, revealing a dramatic inhibition of glioma tumor growth, while there was no such reduction of BLI in ELP-KLAK treated mice (Figure 8A and B). There were no significant changes in the body weight of mice during therapy (Figure S7). The excised tumor weights 
A

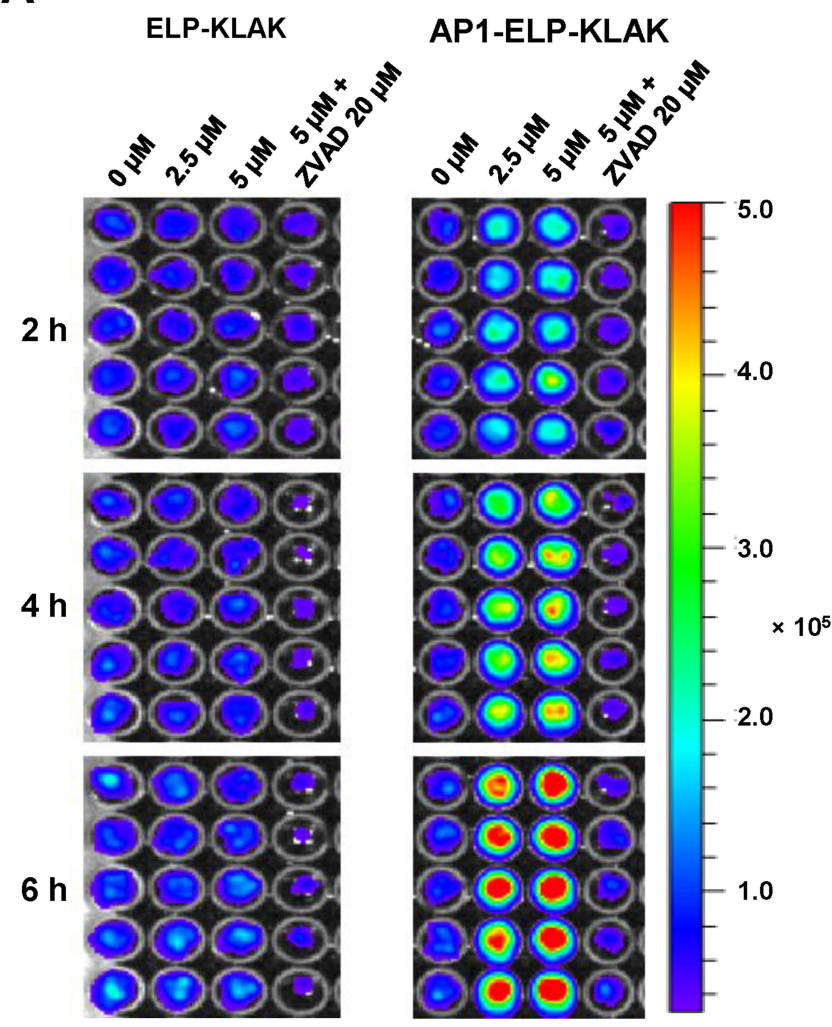

B
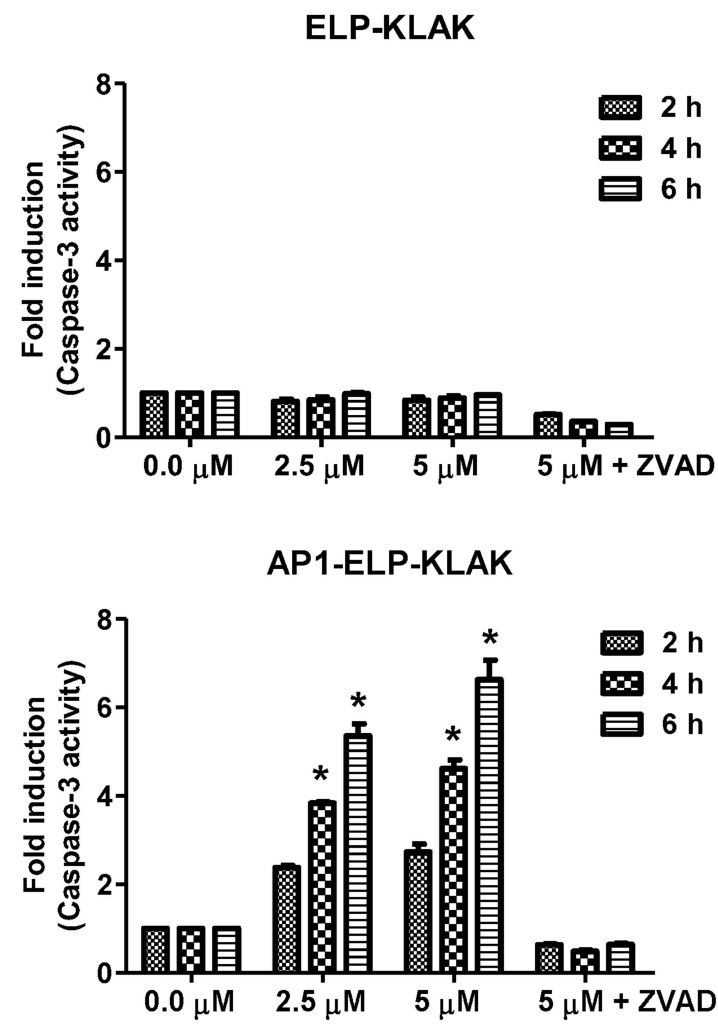

Figure 5 Analysis of caspase activation mediated apoptosis by API-ELP-KLAK in D54/C cells. (A) Bioluminescence imaging (BLI) activity of the caspase-3 sensor was measured following the treatment of different concentration apoptotic peptides with or without Z-VAD (caspase inhibitor) to D54/C cells. BLIs were also obtained using an IVIS imaging system post treatment. (B) BLI activity was plotted as the fold induction caspase activation over values obtained from cells treated with PBS only. Experiments were performed at least in triplicate, and mean values \pm s.d. were plotted. The intergroup variation was measured by one-way ANOVA, followed by Bonferroni post hoc test $(* \mathrm{P}<0.05)$.

obtained at the end of therapy were drastically reduced in AP1-ELP-KLAK treated mice when compared with the control and ELP-KLAK groups (Figure 8C). In addition, when TUNEL assay was performed using the excised tumors, a significant number of apoptotic cells were seen in the tumor tissues of the AP1-ELP-KLAK treated tumor but not in the control treated tumors (Figure 8D). Taken together, AP1-ELP polymer efficiently delivered the KLAK, inducing vast apoptosis to IL-4R expressing tumor tissues by active targeting of receptor-mediated endocytosis and passive EPR effect at the leaky tumor site.

\section{Discussion}

Glioblastoma multiforme (GBM) is a high grade human brain tumor with poor prognosis after chemotherapy and radiation therapy. ${ }^{36-39}$ Thus, new active targeting modalities by targeting overexpressed receptors or antigen molecules on tumor cell surfaces are highly recommended. IL-4R mediated targeted delivery of cytotoxin and anti-cancer drugs has shown a tremendous antitumor effect in human GBM bearing mice. ${ }^{40}$ Here, we successfully targeted IL-4R overexpressing glioblastoma cells/tumor with AP1-ELPKLAK and monitored apoptosis using a caspase 3 sensor in a non-invasive manner. Intracellular localization of KLAK peptide is essential to trigger the apoptotic program of cell death by disrupting the mitochondrial membrane integrity. ${ }^{41-43}$ As an ideal delivery system, AP1-ELP facilitates cellular uptake based on IL-4R mediated endocytosis and delivers the KLAK peptide, causing apoptosis. The apoptosis induced by the polypeptides was monitored using our previously engineered caspase sensor. ${ }^{29,30}$ It can be noted that after AP1-ELPKLAK treatment in D54/C cell lines, BLI activity of the caspase-3 sensor started to increase as early as after $2 \mathrm{~h}$ and continue to increase with more incubation time indicating that the presence of AP1 hastens the 
A

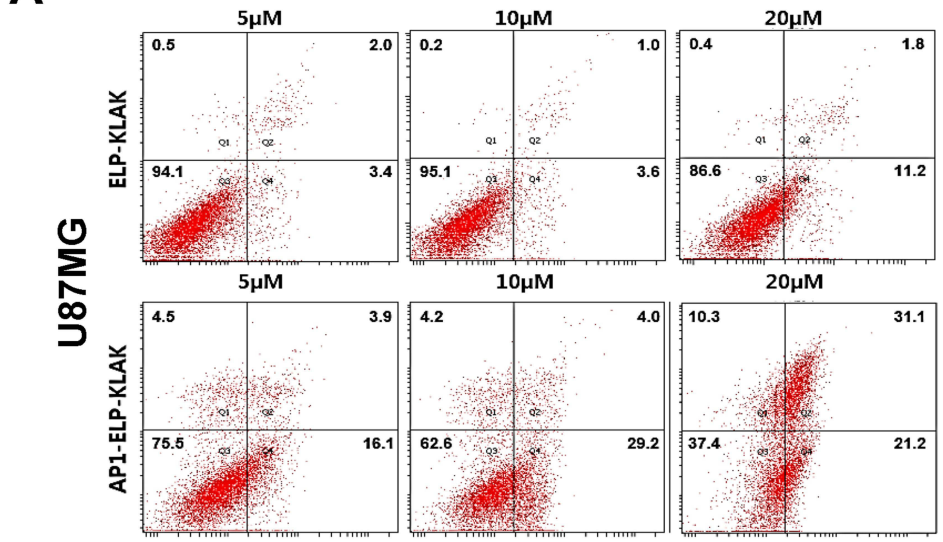

C

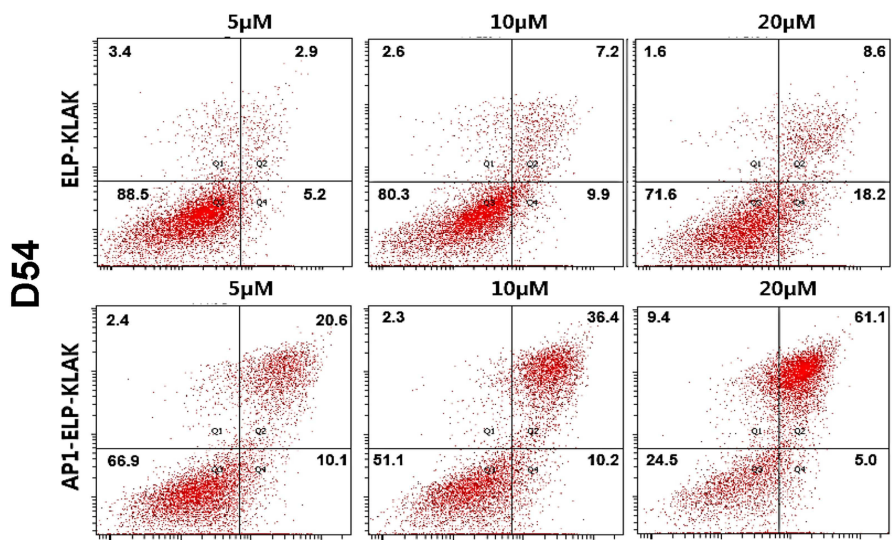

B

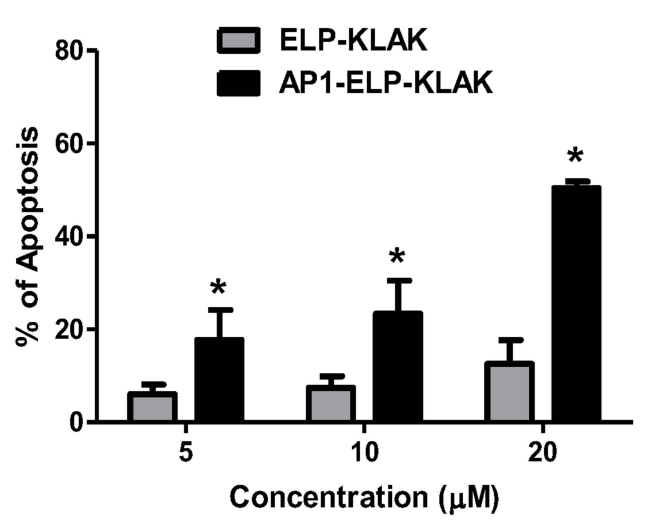

D

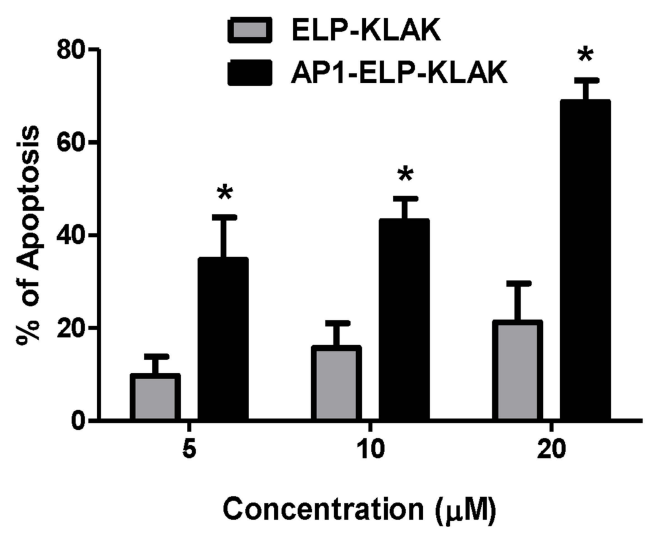

Figure 6 API-ELP-KLAK induced apoptosis in glioblastoma cells. (A and C) U87MG/effluc cells, (B and D) D54/effluc cells. The percentage of apoptotic cells stained with annexin $\mathrm{V}$ conjugated to green-fluorescent FITC dye and dead cells with propidium iodide (PI) were measured by flow cytometry. Representative data of three independent experiments, mean \pm s.d. $(n=5)$. Percentage of apoptosis significantly increased in API-ELP-KLAK treated cells at all given concentrations. $* P<0.05$ (one-way ANOVA).

apoptotic process of D54/C through IL-4R mediated endocytosis (Figure 5). However, such early increase of BLI activity was not seen even after $6 \mathrm{~h}$ of treatment of ELP-KLAK. The decrease in BLI (caspase-3 activity) to basal level on addition of Z-VAD (caspase inhibitor) further confirmed the selectivity and sensitivity of the caspase-3 reporter. Moreover, this caspase-3 reporter system allows us the real time monitoring of apoptosis continuously up to 72 hor $96 \mathrm{~h}$ in a single $96-$-well plate. The hindrance in the development of potential anticancer drugs is the lack of consistency in preclinical assessment of therapeutic efficacy. The traditional volumetric measurement of tumor size is time-consuming and prone to human error. Therefore, the non-invasive approach of measuring apoptosis in real time using a caspase sensor helps to decide the therapeutic strategies including dose and time interval of anti-cancer drugs or peptide treatment. Herein, we successfully measured apoptosis in a non-invasive manner of D54/C glioma cells after AP1-ELP-KLAK treatment in vivo and further confirmed the apoptosis by ex vivo immunohistochemical staining of excised tumor with anticleaved caspase-3 antibody (Figure 7). The drastic reduction of tumor growth upon AP1-ELP-KLAK treatment may be due to enhanced tumor accumulation by the active targeting of IL-4R on D54 tumors and passive EPR effect. As expected, tumor volume increases drastically in PBS and AP1-ELP treated mice, which corresponds to the significant increase in BLI activity at indicated time intervals for more than 45 days. The lack of targeting molecules in ELP-KLAK possibly results in rapid clearance from the system, thus displayed less anti-tumor effect in treated mice. Current strategies used for treatment of brain tumors normally do not carry targeting properties and therefore are reported to have various toxicity problems. ${ }^{44}$ As a result, surface receptors that are over-expressed on glioma cells could serve as molecules of interest for 
A

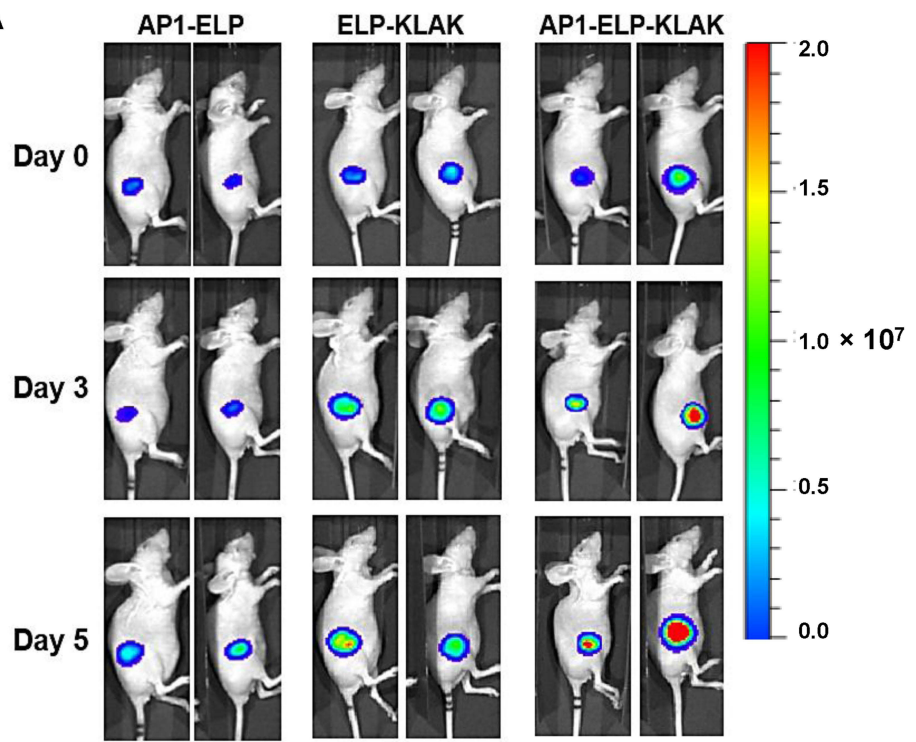

C

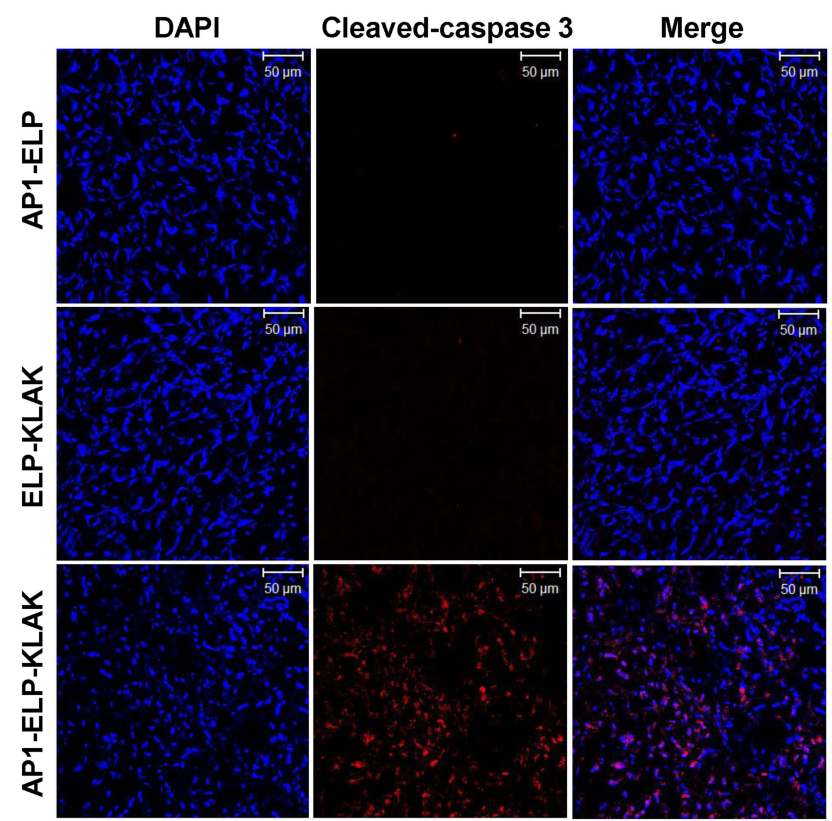

B

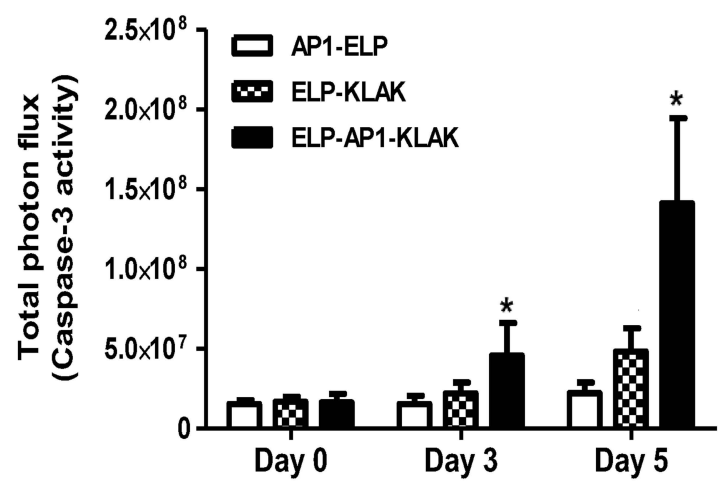

Figure 7 Non-invasive imaging of caspase activation in vivo. (A) BLI of caspase-3 activity after the IV injection of either ELP-KLAK and API-ELP-KLAK in D54/C tumorbearing mice. (B) Quantification of caspase-3 sensor BLI activity. Experiments were conducted in triplicate, and the mean values \pm s.d. were plotted. Significant increase in caspase-3 activity was observed in API-ELP-KLAK treated mice at all time points, $* \mathrm{P}<0.01$ (two-way ANOVA). (C) At day 6 , mice were sacrificed and ex vivo staining of excised tumor tissues were done with anti-cleaved-Caspase-3 (red), followed by counter staining with DAPI for nuclei (blue). Scale bar, $50 \mu \mathrm{m}$.

active targeting with potent nanomedicine. Even though we have successfully delivered the therapeutic peptides and inhibited tumor progression in the glioma xenograft model, more detailed evaluation of the therapeutic effect in an orthotropic glioma mice model is necessary to fully validate its biomedical applications.

\section{Conclusion}

In this study, non-invasive monitoring of apoptosis and tumor growth was investigated using a different reporter system in a glioblastoma mice model. Glioblastoma is known to have high expression of IL-4R; hence, we successfully evaluated the therapeutic outcome of our multivalent based drug delivery system AP1-ELP-KLAK in a glioma mice model. Further studies on nano-formulation or conjugation of FDA approved chemotherapeutic drugs with AP1ELP will provide a significant opportunity to enhance drug delivery across the blood-brain barrier, and for targeting glioma cells. Overall, the non-invasive imaging of apoptosis via the caspase-3 biosensor will provide a potential platform 
A

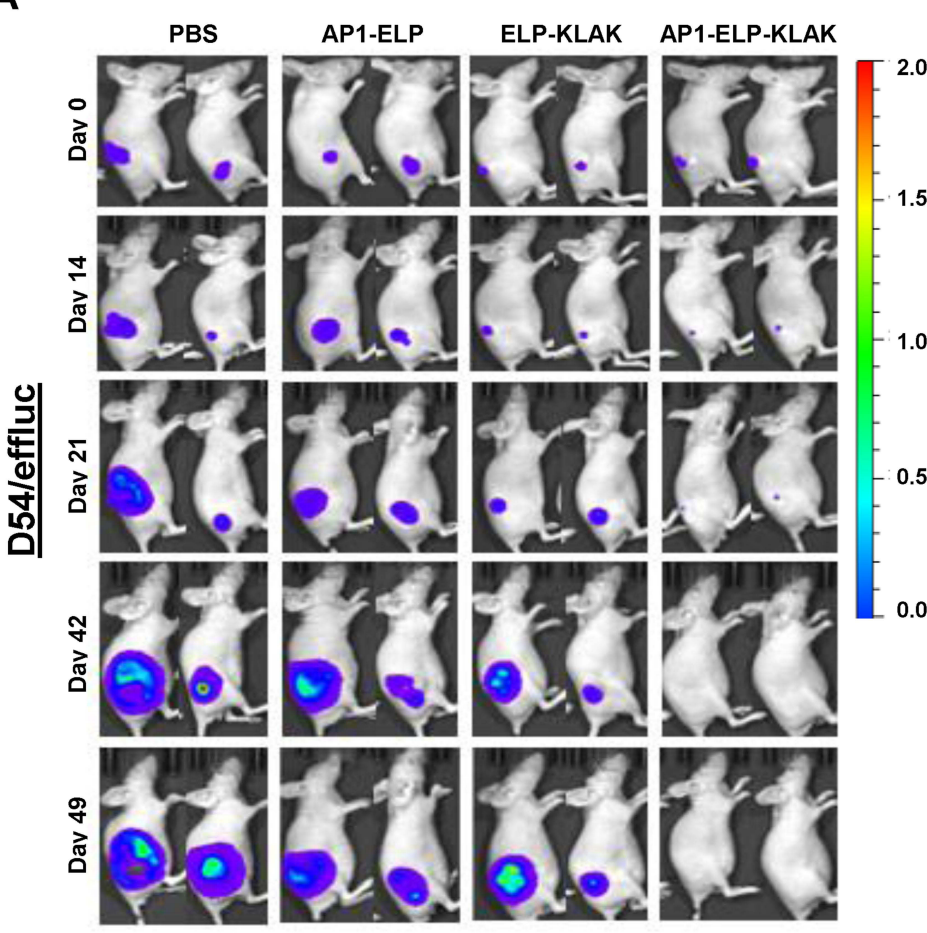

B

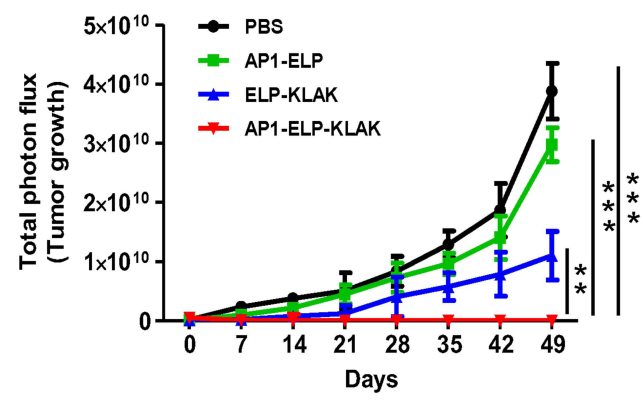

C

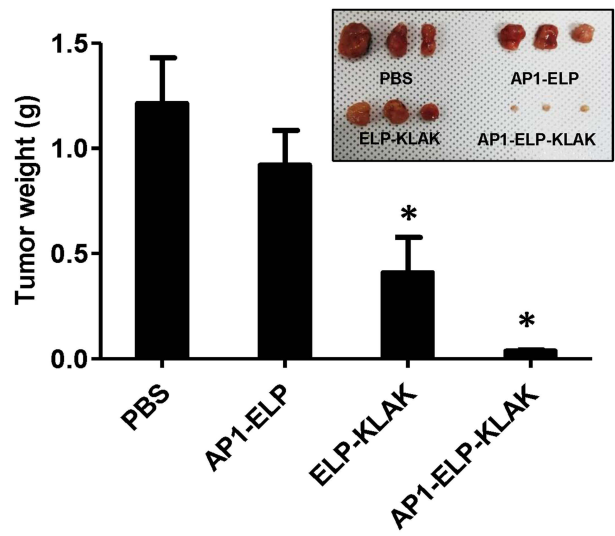

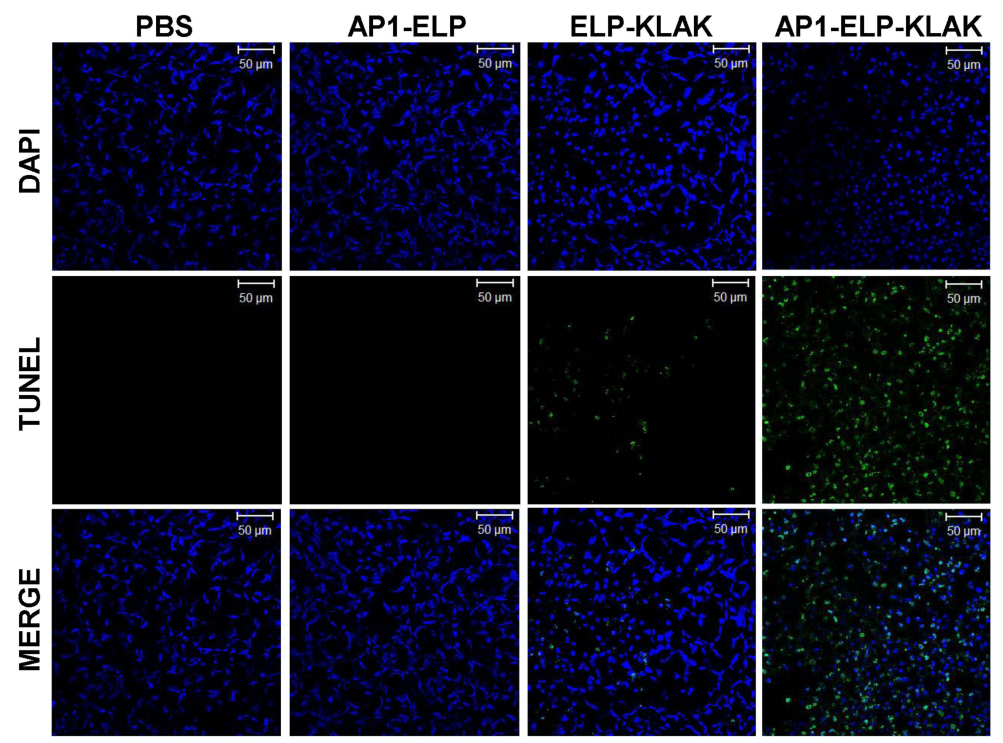

Figure 8 Anti-tumor effect of API-ELP-KLAK in glioma bearing mice. (A and B) D54/effluc bearing mice were intravenously (IV) injected with $150 \mathrm{mg} \mathrm{kg}{ }^{-1}$ of respective polypeptides and control daily for 8 days. BLI (surrogate marker of tumor growth) were obtained after injection of d-luciferin at indicated time $(n=10)$. A significant reduction of BLI of effluc was obtained in API-ELP-KLAK treated mice, revealing a dramatic inhibition of glioma tumor growth, while no such BLI reduction was seen in ELP-KLAK treated mice, ***P<0.00I, significant difference for API-ELP-KLAK compared with PBS, API-ELP; **P<0.0I, significant difference for API-ELP-KLAK compared with ELP-KLAK (two-way ANOVA). (C) The excised tumor weights obtained at the end of therapy were significantly reduced in API-ELP-KLAK treated mice but not in control and ELP-KLAK groups. Data are represented as mean \pm s.d. $(n=10)$. *P<0.0I (Student's $t$-test). (D) Excised tumor tissues showing TUNEL positive apoptotic cells (green) and (blue), as nuclei; Scale bar, $50 \mu \mathrm{m}$.

in preclinical trials and offer a window for the real-time evaluation of therapeutic protocols during cancer therapy.

\section{Supplementary Materials}

Supplementary information accompanies this paper at journal website.

\section{Acknowledgment}

This study was supported by National Research Foundation of Korea (NRF), Korea government (MSIT), Grant (No.2021R1A5A2021614), and Indian Council of Medical Research (ICMR), No. 34/17/2019-TF/Nano/ BMS, New Delhi, India. 


\section{Author Contributions}

VS and AY equally contributed to this work. RWP and TDS supervised the project. All authors made a significant contribution to the work reported, whether that is in the conception, study design, execution, acquisition of data, analysis and interpretation, or in all these areas; took part in drafting, revising or critically reviewing the article; gave final approval of the version to be published; have agreed on the journal to which the article has been submitted; and agree to be accountable for all aspects of the work.

\section{Disclosure}

All authors declare no conflicts of interest in this work.

\section{References}

1. Jain RK. Delivery of molecular and cellular medicine to solid tumors. Adv Drug Deliv Rev. 2001;46:149-168. doi:10.1016/s0169-409x(00) 00131-9

2. Moses MA, Brem H, Langer R. Advancing the field of drug delivery: taking aim at cancer. Cancer Cell. 2003;4(5):337-341. doi:10.1016/ s1535-6108(03)00276-9

3. Allen TM, Cullis PR. Drug delivery systems: entering the mainstream. Science. 2004;303(5665):1818-1822. doi:10.1126/ science. 1095833

4. Frandsen JL, Ghandehari H. Recombinant protein-based polymers for advanced drug delivery. Chem Soc Rev. 2012;41(7):2696-2706. doi:10.1039/c2cs15303c

5. Meyer DE, Chilkoti A. Genetically encoded synthesis of protein-based polymers with precisely specified molecular weight and sequence by recursive directional ligation: examples from the elastin-like polypeptide system. Biomacromolecules. 2002;3 (2):357-367. doi:10.1021/bm015630n

6. Floss DM, Schallau K, Rose-John S, et al. Elastin-like polypeptides revolutionize recombinant protein expression and their biomedical application. Trends Biotechnol. 2010;28(1):37-45. doi:10.1016/j. tibtech.2009.10.004

7. Urry DW, Parker TM, Reid MC, et al. Biocompatibility of the bioelastic materials, Poly(GVGVP) and its $\gamma$-irradiation cross-linked matrix: summary of generic biological test results. J Bioact Compat Polym. 1991;6:263-282. doi:10.1177/088391159100600306

8. Shamji MF, Betre H, Kraus VB, et al. Development and characterization of a fusion protein between thermally responsive elastin-like polypeptide and interleukin-1 receptor antagonist: sustained release of a local antiinflammatory therapeutic. Arthritis Rheum. 2007;56 (11):3650-3661. doi:10.1002/art.22952

9. Liu W, Dreher MR, Furgeson DY, et al. Tumor accumulation, degradation and pharmacokinetics of elastin-like polypeptides in nude mice. J Control Release. 2006;116(2):170-178. doi:10.1016/j. jconrel.2006.06.026

10. McDaniel JR, Callahan DJ, Chilkoti A. Drug delivery to solid tumors by elastin-like polypeptides. Adv Drug Deliv Rev. 2010;62 (15):1456-1467. doi:10.1016/j.addr.2010.05.004

11. Cappello J, Ghandehari H. Engineered protein polymers for drug delivery and biomedical applications. Adv Drug Deliv Rev. 2002;54. doi:10.1016/S0169-409X(02)00057-1

12. Dreher MR, Simnick AJ, Fischer K, et al. Temperature triggered self-assembly of polypeptides into multivalent spherical micelles. J Am Chem Soc. 2008;130(2):687-694. doi:10.1021/ja0764862
13. Liu W, MacKay JA, Dreher MR, et al. Injectable intratumoral depot of thermally responsive polypeptide-radionuclide conjugates delays tumor progression in a mouse model. $J$ Control Release. 2010;144:2-9. doi:10.1016/j.jconrel.2010.01.032

14. Meyer DE, Chilkoti A. Quantification of the effects of chain length and concentration on the thermal behavior of elastin-like polypeptides. Biomacromolecules. 2004;5(3):846-851. doi:10.1021/ bm034215n

15. Bidwell GL 3rd, Raucher D. Cell penetrating elastin-like polypeptides for therapeutic peptide delivery. Adv Drug Deliv Rev. 2010;62 (15):1486-1496. doi:10.1016/j.addr.2010.05.003

16. Kim W, Chaikof EL. Recombinant elastin-mimetic biomaterials: emerging applications in medicine. Adv Drug Deliv Rev. 2010;62 (15):1468-1478. doi:10.1016/j.addr.2010.04.007

17. Dreher MR, Raucher D, Balu N, et al. Evaluation of an elastin-like polypeptide-doxorubicin conjugate for cancer therapy. $J$ Control Release. 2003;91:31-43. doi:10.1016/s0168-3659(03)00216-5

18. MacKay JA, Chen M, McDaniel JR, et al. Self-assembling chimeric polypeptide-doxorubicin conjugate nanoparticles that abolish tumours after a single injection. Nat Mater. 2009;8(12):993-999. doi: $10.1038 /$ nmat2569

19. Ben-Baruch A. Host microenvironment in breast cancer development: inflammatory cells, cytokines and chemokines in breast cancer progression: reciprocal tumor-microenvironment interactions. Breast Cancer Res. 2003;5:31-36. doi:10.1186/bcr554

20. Nelms K, Keegan AD, Zamorano J, et al. The IL-4 receptor: signaling mechanisms and biologic functions. Annu Rev Immunol. 1999;17 (1):701-738. doi:10.1146/annurev.immunol.17.1.701

21. Todaro M, Lombardo Y, Francipane MG, et al. Apoptosis resistance in epithelial tumors is mediated by tumor-cell-derived interleukin-4. Cell Death Differ. 2008;15(4):762-772. doi:10.1038/sj.cdd.4402305

22. Puri RK, Leland P, Obiri NI, et al. An improved circularly permuted interleukin 4-toxin is highly cytotoxic to human renal cell carcinoma cells. Introduction of gamma c chain in RCC cells does not improve sensitivity. Cell Immunol. 1996;171(1):80-86. doi:10.1006/cimm.19 96.0176

23. Hong H-Y, Lee HY, Kwak W, et al. Phage display selection of peptides that home to atherosclerotic plaques: IL-4 receptor as a candidate target in atherosclerosis. J Cell Mol Med. 2008;12 (5b):2003-2014. doi:10.1111/j.1582-4934.2008.00189.x

24. Park K, Hong H-Y, Moon HJ, et al. A new atherosclerotic lesion probe based on hydrophobically modified chitosan nanoparticles functionalized by the atherosclerotic plaque targeted peptides. J Control Release. 2008;128(3):217-223. doi:10.1016/j.jconrel.2008.03.019

25. Sarangthem V, Cho EA, Bae SM, et al. Construction and application of elastin like polypeptide containing IL-4 receptor targeting peptide. PLoS One. 2013;8(12):e81891. doi:10.1371/journal.pone.0081891

26. Joshi BH, Leland $\mathrm{P}$, Asher $\mathrm{A}$, et al. In situ expression of interleukin-4 (IL-4) receptors in human brain tumors and cytotoxicity of a recombinant IL-4 cytotoxin in primary glioblastoma cell cultures. Cancer Res. 2001;61:8058-8061.

27. Puri RK, Leland P, Kreitman RJ, et al. Human neurological cancer cells express interleukin-4 (IL-4) receptors which are targets for the toxic effects of IL4-Pseudomonas exotoxin chimeric protein. Int J Cancer. 1994;58(4):574-581. doi:10.1002/ijc.2910580421

28. Sarangthem V, Kim Y, Singh TD, et al. Multivalent targeting based delivery of therapeutic peptide using AP1-ELP carrier for effective cancer therapy. Theranostics. 2016;6(12):2235-2249. doi:10.7150/ thno. 16425

29. Coppola JM, Ross BD, Rehemtulla A. Noninvasive imaging of apoptosis and its application in cancer therapeutics. Clin Cancer Res. 2008;14(8):2492-2501. doi:10.1158/1078-0432.CCR-07-0782

30. Luker KE, Smith MC, Luker GD, et al. Kinetics of regulated protein-protein interactions revealed with firefly luciferase complementation imaging in cells and living animals. Proc Natl Acad Sci U S A. 2004;101(33):12288-12293. doi:10.1073/pnas.0404041101 
31. Rabinovich BA, Ye Y, Etto T, et al. Visualizing fewer than 10 mouse $\mathrm{T}$ cells with an enhanced firefly luciferase in immunocompetent mouse models of cancer. Proc Natl Acad Sci U S A. 2008;105 (38):14342-14346. doi:10.1073/pnas.0804105105

32. Singh TD, Lee HW, Lee SW, et al. Noninvasive imaging of apoptosis induced by adenovirus-mediated cancer gene therapy using a caspase-3 biosensor in living subjects. Mol Imaging. 2014;13. doi:10.2310/7290.2014.00019

33. Lee HW, Singh TD, Lee S-W, et al. Evaluation of therapeutic effects of natural killer (NK) cell-based immunotherapy in mice using in vivo apoptosis bioimaging with a caspase-3 sensor. FASEB J. 2014;28(7):2932-2941. doi:10.1096/fj.13-243014

34. Meyer DE, Chilkoti A. Purification of recombinant proteins by fusion with thermally-responsive polypeptides. Nat Biotechnol. 1999;17 (11):1112-1115. doi:10.1038/15100

35. Trabbic-Carlson K, Liu L, Kim B, et al. Expression and purification of recombinant proteins from Escherichia coli: comparison of an elastin-like polypeptide fusion with an oligohistidine fusion. Protein Sci. 2009;13(12):3274-3284. doi:10.1110/ps.04931604

36. Verreault M, Strutt D, Masin D, et al. Vascular normalization in orthotopic glioblastoma following intravenous treatment with lipid-based nanoparticulate formulations of irinotecan (Irinophore C), doxorubicin (Caelyx $(\mathrm{R}))$ or vincristine. BMC Cancer. 2011;11:124. doi:10.1186/1471-2407-11-124

37. Tam VH, Sosa C, Liu R, et al. Nanomedicine as a non-invasive strategy for drug delivery across the blood brain barrier. Int J Pharm. 2016;515 (1-2):331-342. doi:10.1016/j.ijpharm.2016.10.031
38. Crawford L, Rosch J, Putnam D. Concepts, technologies, and practices for drug delivery past the blood-brain barrier to the central nervous system. J Control Release. 2016;240:251-266. doi:10.1016/ j.jconrel.2015.12.041

39. Quader S, Liu X, Chen Y, et al. cRGD peptide-installed epirubicin-loaded polymeric micelles for effective targeted therapy against brain tumors. $J$ Control Release. 2017;258:56-66. doi:10.1016/j.jconrel.2017.04.033

40. Yang F-Y, Wong -T-T, Teng M-C, et al. Focused ultrasound and interleukin-4 receptor-targeted liposomal doxorubicin for enhanced targeted drug delivery and antitumor effect in glioblastoma multiforme. J Control Release. 2012;160(3):652-658. doi:10.1016/j. jconrel.2012.02.023

41. Javadpour MM, Juban MM, Lo WC, et al. De novo antimicrobial peptides with low mammalian cell toxicity. $J$ Med Chem. 1996;39:3107-3113. doi:10.1021/jm9509410

42. Ellerby HM, Arap W, Ellerby LM, et al. Anti-cancer activity of targeted pro-apoptotic peptides. Nat Med. 1999;5(9):1032-1038. doi:10.1038/12469

43. Mai JC, Mi Z, Kim SH, et al. A proapoptotic peptide for the treatment of solid tumors. Cancer Res. 2001;61:7709-7712.

44. Zhang F, Lin Y-A, Kannan S, et al. Targeting specific cells in the brain with nanomedicines for CNS therapies. $J$ Control Release. 2016;240:212-226. doi:10.1016/j.jconrel. 2015.12.013
International Journal of Nanomedicine

\section{Publish your work in this journal}

The International Journal of Nanomedicine is an international, peerreviewed journal focusing on the application of nanotechnology in diagnostics, therapeutics, and drug delivery systems throughout the biomedical field. This journal is indexed on PubMed Central, MedLine, CAS, SciSearch ${ }^{\mathbb{}}$, Current Contents ${ }^{\mathbb{R}} /$ Clinical Medicine, $^{2}$

\section{Dovepress}

Journal Citation Reports/Science Edition, EMBase, Scopus and the Elsevier Bibliographic databases. The manuscript management system is completely online and includes a very quick and fair peer-review system, which is all easy to use. Visit http://www.dovepress.com/ testimonials.php to read real quotes from published authors. 